\title{
Correction to: Engineering of Novel Fe-Based Bulk Metallic Glasses Using a Machine Learning-Based Approach
}

\author{
Tzu-Chia Chen ${ }^{1}$ - Rajiman Rajiman ${ }^{2}$ - Marischa Elveny ${ }^{3}$. John William Grimaldo Guerrero ${ }^{4}$. \\ Adedoyin Isola Lawal ${ }^{5,6}$. Ngakan Ketut Acwin Dwijendra ${ }^{7}$. Aravindhan Surendar ${ }^{8}$. \\ Svetlana Dmitrievna Danshina ${ }^{9} \cdot \mathrm{Yu}_{\mathrm{Zhu}}{ }^{10}$
}

Published online: 21 September 2021

(c) King Fahd University of Petroleum \& Minerals 2021

\section{Correction to: \\ Arabian Journal for Science and Engineering https://doi.org/10.1007/s13369-021-05966-0}

In the original publication, the affiliation of author, Dr. Svetlana Dmitrievna Danshina was wrong. The correct affiliation should be "Sechenov First Moscow State Medical University, Moscow, Russia". The original publication has been corrected.

\footnotetext{
The original article can be found online at https://doi.org/10.1007/ s13369-021-05966-0.

Marischa Elveny

marischaelveny@usu.ac.id

$凶$ Yu Zhu

yuzhu6494@gmail.com

Tzu-Chia Chen

tzuchiachen1688@gmail.com

Svetlana Dmitrievna Danshina

sfmsmu@mail.ru

1 CAIC, DPU, Bangkok, Thailand

2 Universitas Bandar Lampung, Bandar Lampung, Indonesia

3 Data Science and Computational Intelligence Research Group, Universitas Sumatera Utara, Medan, Indonesia

4 Department of Energy, Universidad de la Costa, Barranquilla, Colombia

5 Department of Accounting and Finance, Landmark University, Omu-Aran, Nigeria

6 Sustainable Development Goal 17 (Partnership for the Goals) Research Cluster, Landmark University, Omu-Aran, Nigeria

7 Faculty of Engineering, Udayana University, Bali, Indonesia

8 Saveetha Institute of Medical and Technical Sciences, Chennai, India

9 Sechenov First Moscow State Medical University, Moscow, Russia
}

10 School of Mechanical Engineering, Jiangsu University, Zhenjiang 212013, Jiangsu, China 